\title{
CLINICAL AND RADIOGRAPHIC EVALUATION OF THE EFFECT OF SALVADORA PERSICA AS A PULPOTOMY MEDICAMENT VERSUS FORMOCRESOL AND CALCIUM HYDROXIDE
}

\author{
Mohammad El-Sayed Moteea**, Ibrahim Farouk Barakat ${ }^{* *}$, Samy Yousef El Bayomy***, \\ Amany Mohammed Tawfik ****
}

\begin{abstract}
Objective: The objective of this study was to compare between the clinical and radiographic effects of three medicaments (Salvadora Persica "SP", Formocresol and Calcium hydroxide) on non-vital pulpotomy of primary and young permanent molars. Materials and Methods: The present study was a randomized controlled study comprised of 24 children. These teeth were classified into two equal groups. The patients were with age from 4-8 years old. In (Group 1) the radicular pulp of the primary teeth was capped with formocresol in (subgroup 1A) and SP in (subgroup 1B) after pulpotomy procedures. In (Group 2) the radicular pulp of young permanent molar was capped with calcium hydroxide in (subgroup 2A) and SP in (subgroup 2B) after pulpotomy procedures. The teeth were assessed clinically and radiographically after 3 months. Result: The present study revealed that, in (Group1) the clinical and radiographic success rate of salvadora persica was $83.3 \%$, while the success rate of formocresol was $100 \%$. In (Group2) SP showed no success as a pulpotomy medicament for vital pulpotomy of young permanent molars. Conclusion: Salvadora Persica proved good clinical and radiographic result as a pulp medicament for non-vital pulpotomy of primary molars. Salvadora Persica showed no success as a pulpotomy medicament for vital pulpotomy of young permanent molars.
\end{abstract}

KEYWORDS: Primary molar, young permanent molar, pulpotomy, SP, formocresol, calcium hydroxide.

\section{INTRODUCTION}

Different types of pulp treatment procedures have been recommended for primary teeth. Successful pulpal therapy in primary dentition requires a comprehensive understanding of tooth development, aetiology and pathogenesis of the pulp and the periradicular tissues. Pulpotomy involves amputation of the coronal portion of affected or infected dental pulp ${ }^{(\mathbf{1})}$.
Pulpotomy has become the dominating pulp therapy for the deciduous dentition, because of the complicated anatomy of the root canals in primary teeth, the proximity of the permanent tooth germ and the difficulties in finding a root-canal filling material compatible with physiological root resorption. Pulpotomy therapy for the primary dentition has developed along three lines: devitalization, preservation, and regeneration ${ }^{(\mathbf{1})}$.

\footnotetext{
*Assistant lecturer, Department of Pedodontics and Oral Health (Assuit Branch), Al-Azhar University

** Assistant Professor, and Head Department of Pedodontics and Oral Health, Faculty of Dental Medicine, Boys, Cairo, Al-Azhar University

${ }^{* * *}$ Professor, Department of Pedodontics and Oral Health, Faculty of Dental Medicine, Boys, Cairo, Al-Azhar University

**** Assistant Professor, Department of Microbiology, Faculty of Medicine, Girls, Cairo, Al-Azhar University

-Corresponding author: moh_moteea@yahoo.com
} 
A pulpotomy is performed in a primary tooth with extensive caries but without evidence of radicular pathology when caries removal results in a carious or mechanical pulp exposure. The coronal pulp is amputated, and the remaining vital radicular pulp tissue surface is treated with a long-term clinically-successful medicament such as Buckley's Solution of formocresol or ferric sulfate. Pulpotomy using formocresol was introduced by Buckley in 1904. Since then various modifications have been tried and advocated regarding the techniques of FC pulpotomy and the concentrations ${ }^{(2)}$.

Calcium hydroxide was the first agent used in pulpotomies that demonstrated any capacity to induce regeneration of dentin. The rationale that prompted its use was fundamentally erroneous; he attributed the action of calcium hydroxide to a modification of the solubility product of calcium, phosphate and a precipitation of salt into an organic matrix. The main drawback of this alternative intervention is internal resorption. $70 \%$ success rate was reported by Subramaniam with the use of thick paste of Calcium hydroxide and water ${ }^{(3)}$.

Studies evaluated clinically and microbiologically the effect of calcium hydroxide $(\mathrm{CH})$ on carious dentin on primary teeth submitted to indirect pulp capping (IPC). They concluded that the resin-based composite sealing of dentin caries lesions in primary teeth, with or without calcium hydroxide liner over the infected remaining tissue, may help preserve dental tissue as well as pulp vitality ${ }^{(4)}$.

Salvadora persica is commonly known as miswak tree since it is the most common source of miswak and extensively used among the 182 species of plants used as chewing sticks across the world ${ }^{(5)}$.

Studies investigated the efficacy of miswak in preventing dental caries. They showed a significant increase in DMFT in the control group. There was $55 \%$ increase in the rate of dental caries in control group compared to case group ( 0.89 before the study and 1.38 after the study). The risk of dental caries for each tooth in control group was 9.35 times more than case group ( $9.14 \%$ and $0.98 \%$ respectively). Dental caries rate was detected slightly less in the case group at the end of this study. This might be as a result of the antimicrobial effects of miswak ${ }^{(6)}$.

\section{SUBJECTS AND METHODS}

\section{Study setting and population:}

This study was a randomized non-blinded controlled study comprised of 24 children indicated for non-vital pulp therapy of primary molars (12) and vital pulp therapy (12) of young permanent molars (Clinical, radiogaphical and microbiological).

The patients were selected from the Outpatient Clinic of Department of Pedodontics and Preventive Dentistry, Faculty of Dentistry, Al-Azhar University, Assiut Branch. This study was carried out with informed consent of the caregiver. Informed consent forms were signed by all patients ${ }^{\text {ee }}$ parents participating in this study.

\section{Eligibility criteria:}

All children should be with good general health and no history of systemic illness or hospitalization according to the follow criteria:

\section{Group 1:}

\section{Inclusion criteria:}

- Patient's and parental cooperation

- Absence of any systemic disease which would contraindicate pulp therapy

- No previous history of antibiotic therapy for at least 2 weeks

- Presence of clinical signs or symptoms suggesting a non-vital tooth, such as localized swelling, suppurating sinus, tenderness on percussion, or slight mobility

- Possibility for establishing a final restoration of the tooth. 


\section{Radiographic criteria:}

- No pathological external or internal root resorption

- No periodical radiolucency

- No calcific pulp degeneration.

\section{Group 2:}

\section{Inclusion criteria:}

All patients selected for this study were free from any systemic diseases. Each tooth chosen for pulpotomy (apexogenesis) met the following criteria:

1. The tooth was immature with incomplete root formation and damage to the coronal pulp, but with a presumed healthy radicular pulp.

2. The crown was fairly intact and restorable.

3. There was no clinical evidence of extensive pulp degeneration or periapical pathology, including spontaneous throbbing pain, tenderness to percussion, tooth mobility, swelling, or fistulous tract.

4. There was no radiographic evidence of periapical pathosis or inter- radicular bone loss, internal resorption, pulp calcification, ankylosis, or pathologic external root resorption.

\section{Radiographic criteria:}

Preoperative periapical radiographs of the teeth considered for treatment in the study were made using the $\mathrm{XCP}$ extension cone paralleling technique.

\section{Intervention:}

Molars to be treated were locally anaesthetized using mepecaine-L (a local anesthetic solution containing $20 \mathrm{mg}$ Mepivacaine hydrochloride with 0.06 $\mathrm{mg}$ Levonordefrin hydrochloride). Patients were allowed to wait for 10-15 min before performing the pulpotomy procedure. Rubber dam was used to isolate the designated molar. Cavity outline was established with a sterile \#330 high-speed pear- shaped carbide bur with air/water spray. Caries was removed with a slow speed sterile round carbide bur. Access to a pulp chamber was detected with a probe, or if the roof of the pulp chamber was sufficiently thin to see the pulpal tissue. When the pulpal exposure was confirmed, the roof of the pulp chamber was removed with a sterile, non-end cutting slow-speed bur. Removal of the coronal pulp tissue was achieved with a sterile low-speed carbide round bur and/or sharp, large, spoon excavator. Hemostasis was attained by placing small cotton pellet moistened in sterile saline with slight pressure then it was removed.

The selected molars were divided into two groups:

Group 1 (non-vital pulpotomy of primary teeth):

- Subgroup 1A: 12 primary molars using formocresol as a pulpotomy medicament.

- Subgroup 1B: 12 primary molars using Salvadora persica as a pulpotomy medicament.

Group 2 (vital pulpotomy of young permanent teeth):

- Subgroup 2A: 12 first permanent molars using calcium hydroxide as a pulpotomy medicament.

- Subgroup 2B: 12 first permanent molars using Salvadora persica as a pulpotomy medicament.

\section{Ethical consideration:}

The study was approved by the Pedodontics scientific Committee and department council, Faculty of Dental Medicine, Boys, Cairo, ALAzhar University. A signed informed consent will be obtained from the parents of each child prior to entry into the study.

\section{Data management and analysis:}

Statistical Package of Social science version 21 was used for data management and data analysis. Data were explored for normality using Kolmogorov-Smirnov and Shapiro-Wilk tests, data showed parametric (normal) distribution. For parametric data; independent $t$ test was used to 
compare between two groups in related samples, the significance level was set at $\mathrm{P} \leq 0.05$.

\section{RESULTS}

\section{Group (I):}

\section{Clinical evaluation results}

Clinical evaluation of primary molars treated with Formocresol and Salvadora persica after three months. There was no statistically significant difference between (Group A) and (Group B) in Pain, Percussion, Mobility, Swelling and Development of sinus where $(p=1)$; (Table 1$)$.

TABLE (1): The frequencies of clinical outcomes of different groups in three months' time period.

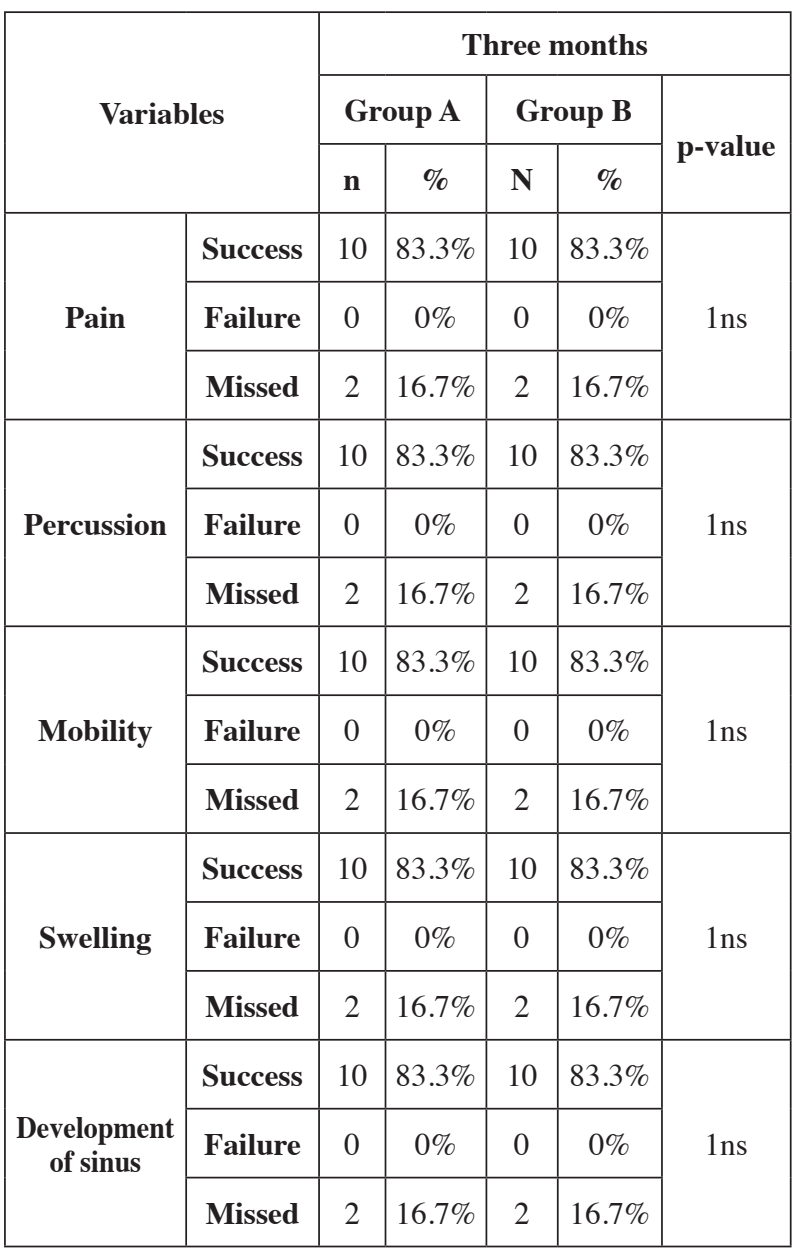

*; significant $(p<0.05)$

$n s ;$ non-significant $(p>0.05)$

\section{Radiographic evaluation results}

Radiographic evaluation of primary molars treated with Formocresol and Salvadora persica after three months. There was no statistically significant difference between (Group A) and (Group B) in Radiolucency, PDL Widening and IRR or ERR where $(p=1)$; (Fig. 1).

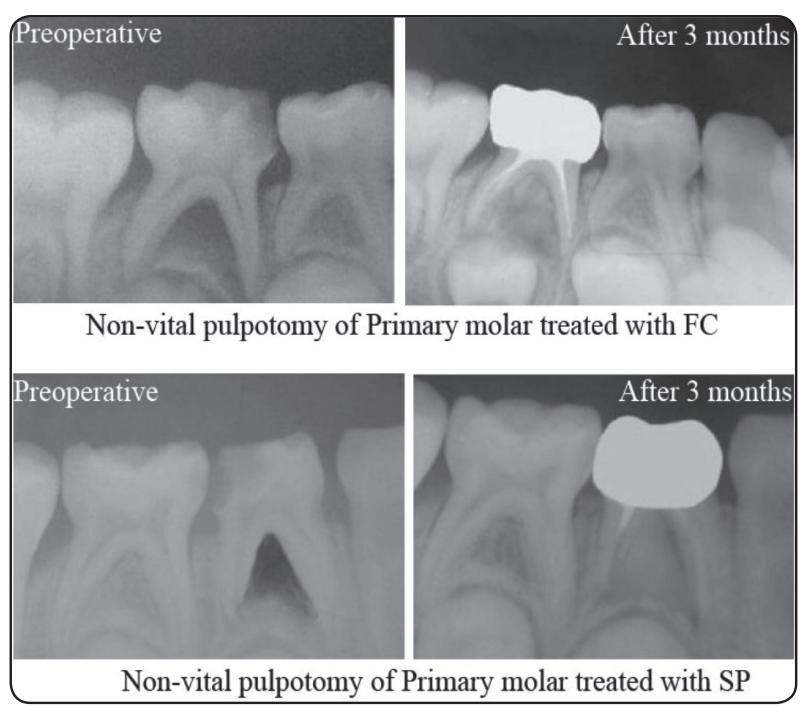

FIG (1) Radiographic features of non-vital pulpotomy of Primary molar treated with (FC) and (SP) showing no signs of failure

\section{Group II:}

\section{Clinical evaluation results}

Clinical evaluation of first permanent molars treated with calcium hydroxide and Salvadora persica after three months. There was no statistically significant difference between (Group A) and (Group B) in Pain, Swelling and Development of sinus where $(p=0.148)$. 
TABLE (2): The frequencies of clinical outcomes of different groups in three months' time period.

\begin{tabular}{|c|c|c|c|c|c|c|}
\hline & & \multicolumn{5}{|c|}{ Three months } \\
\hline \multicolumn{2}{|c|}{ Variables } & \multicolumn{2}{|c|}{ Group A } & \multicolumn{2}{|c|}{ Group B } & \multirow{2}{*}{ p-value } \\
\hline & & $\mathbf{n}$ & $\%$ & $\mathbf{N}$ & $\%$ & \\
\hline \multirow{3}{*}{ Pain } & Success & 12 & $100 \%$ & 10 & $83.3 \%$ & \multirow{3}{*}{$0.148 \mathrm{~ns}$} \\
\hline & Failure & 0 & $0 \%$ & 0 & $0 \%$ & \\
\hline & Missed & 0 & $0 \%$ & 2 & $16.7 \%$ & \\
\hline \multirow{3}{*}{ Swelling } & Success & 12 & $100 \%$ & 10 & $83.3 \%$ & \multirow{3}{*}{$0.148 \mathrm{~ns}$} \\
\hline & Failure & 0 & $0 \%$ & 0 & $0 \%$ & \\
\hline & Missed & 0 & $0 \%$ & 2 & $16.7 \%$ & \\
\hline \multirow{3}{*}{$\begin{array}{l}\text { Development of } \\
\text { sinus }\end{array}$} & Success & 12 & $100 \%$ & 10 & $83.3 \%$ & \multirow{3}{*}{$0.148 \mathrm{~ns}$} \\
\hline & Failure & 0 & $0 \%$ & 0 & $0 \%$ & \\
\hline & Missed & 0 & $0 \%$ & 2 & $16.7 \%$ & \\
\hline
\end{tabular}

*; significant $(p<0.05)$ ns; non-significant $(p>0.05)$

\section{Radiographic evaluation results}

Radiographic evaluation of first permanent molars treated with calcium hydroxide and Salvadora persica after three months. There was a statistically significant difference between (Group A) and (Group B) in Growth root where $(p=0.002)$.

There was no statistically significant difference between (Group A) and (Group B) in PD ligament, Periapical region and IRR or ERR where $(p=0.148)$; (Fig. 2).

\section{DISCUSSION}

In the present trial, (Group 1) (non-vital pulpotomy of primary teeth), the results revealed that the success rate of salvadora persica was $83.3 \%$, while the success rate of formocresol was $100 \%$.

Regarding antibacterial activity, there were statistically significant differences between before and after treatment regarding streptococcus, lactobacilli and EF in groups A and B ( $<<0001)$, but there was no statistically significant difference between group A and group B regarding percentage of bacterial reduction $(\mathrm{p}>0.05)$.

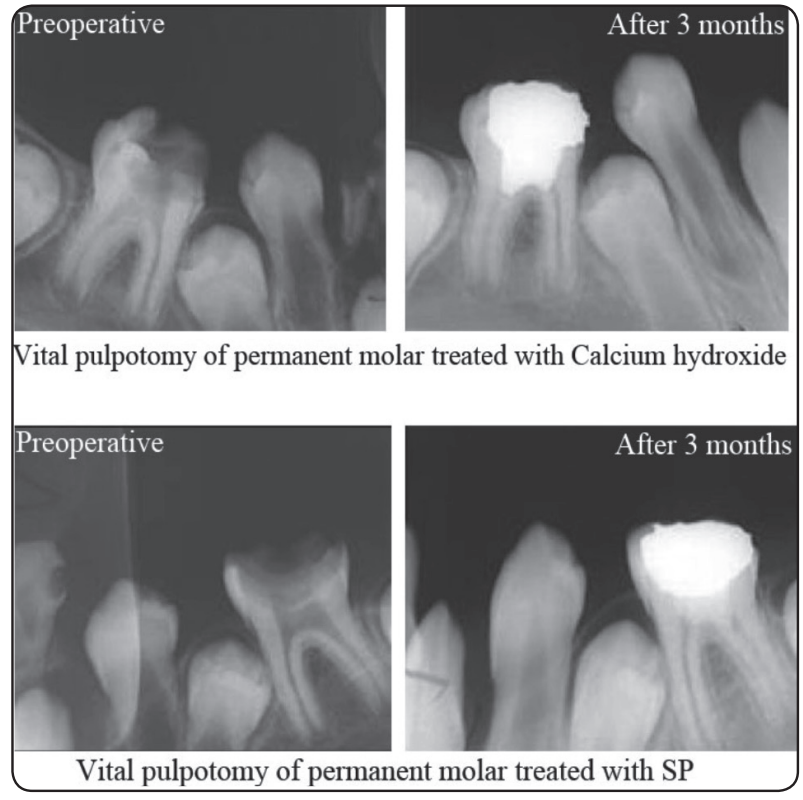

FIG (2) Radiographic features of vital pulpotomy of permanent molar treated with $\left(\mathrm{Ca}(\mathrm{OH})_{2}\right)$ and $(\mathrm{SP})$ 
Fallah et al. ${ }^{(7)}$ have reported the antibacterial and antifungal effects of miswak on cariogenic bacteria and periodontal pathogens including Staphylococcus aureus, Streptococcus mutans, Streptococcus faecalis, Streptococcus pyogenes, Lactobacillus acidophilus, Pseudomonas aeruginosa, Aggregatibacter actinomycetemcomitans, Porphyromonas gingivalis, Haemophilus influenzae, and Candida albicans. Moreover Chelli-Chentouf et al. showed that Salvadora persica extract is also an effective antimicrobial agent when utilized clinically as an irrigant in the endodontic treatment of teeth with necrotic pulps ${ }^{(\mathbf{8})}$.

Wolinsky and Sote showed that S. Persica contains Tri-Methyamin, Salvadrin, Chloride, Fluoride, Silica, Sulfur, Mustard, Vitamin C and a small amount of Saponine Tanin. These components have antibacterial and antifever effects in addition to be against gingival irritation ${ }^{(9)}$. Akpata and Akinrimisi showed that Miswak have strong anti caries effects due to large amounts of fluoride in it. Many dental studies reported antimicrobial activity in derivates from Miswak. In addition, the mechanical cleaning effects of Miswak were investigated and it was reported that the value of chewing sticks is due to their mechanical cleaning ${ }^{(10)}$.

Almas et al. and Al-Lafi \& Ababnch showed that Streptococcus Fecalis is the most sensitive microorganism affected by Miswak ${ }^{(11,12)}$. In addition, Almas showed that Miswak has antimicrobial effects against Streptococcus Mutants and Fecalis ${ }^{(11)}$.

Almas and Al-Zeid investigated the antimicrobial effects of Miswak and its extract specially on Streptococus Mutan and lactobacillus ${ }^{(13)}$. These effects were compared with the effects of toothbrush and normal saline. In Miswak users, there was a significant de-creases in streptococcus $(\mathrm{p}=0.013)$ but not in lactobacillus ( $\mathrm{p}=0.147$ ).

In the present study when salvadora persica was used in this study as a pulpotomy dressing for vital pulpotomy of young permanent teeth
(Group 2) there was no signs of failure clinically except in two cases after 1 month showing swelling and sever pain.

Radiographically, there were no statistically significant differences between group A and group $B$ regarding area of rarefaction, internal resorption, crypt, periapical region and PDL widening after our study time period (one week, 1 month and 3 months), but there were statistically significant differences regarding growth root after 1 month and 3 months in group 2 (vital pulpotomy of young permanent teeth). There was no root growth in all teeth treated with salvadora persica in the three time periods.

This result goes in agreement with the previous study of El-Khodary et al. who compared clinically and radiograohically the dental pulp response when $\mathrm{Ca}(\mathrm{OH})_{2}$ used as a pulpotomy agent in young permanent teeth. They concluded that $\mathrm{Ca}(\mathrm{OH})_{2}$ showed increase in root development and density in relation to baseline ${ }^{(14)}$.

An explanation of the failure of salvadora persica pulpotomy of young permanent teath could be the effect of SP on living cells must be thoroughly investigated as well for its use in the oral environment. Effective dose of a substance is different in microbial and cellular tests and an effective concentration against bacteria may be toxic for cells ${ }^{(15)}$.

No previous study has evaluated the effect of SP extract on hDPSCs. These cells in the connective tissues of the pulp play a central role in the synthesis of the dentinal bridge in some pathologic alterations ${ }^{(16)}$. The diffusion of SP components into pulp through the dentinal tubules should be considered as this can affect DPSCs viability. Darmani et al. evaluated the effects of miswak extracts on the proliferation of mouse fibroblasts using the MTT assay and reported that water extracts of miswak enhanced the growth of fibroblasts while inhibiting the growth of cariogenic bacteria ${ }^{(17)}$. However, Al-Fatimi et al. used neutral red and Ali et al. used alamarBlue ${ }^{\circledR}$ for assessment of the cytotoxicity of $\mathrm{SP}^{(\mathbf{1 8 , 1 9})}$. 
High concentrations of the water extract of SP caused a significant reduction in cell proliferation compared to the negative control group while lower concentrations of water extract increased proliferation of hDPSCs. Increased cell proliferation as the result of exposure to water extract of SP confirms the results of previous studies indicating the optimal efficacy of miswak for improving gingival ulcers ${ }^{(20)}$.

\section{CONCLUSIONS}

- Salvadora Persica proved good clinical and radiographic result as a pulp medicament for non-vital pulpotomy of primary molars.

- Salvadora Persica showed no success as a pulpotomy medicament for vital pulpotomy of young permanenet molars.

\section{REFERENCES}

1. Vijayaalakshmi L. Comparison of ferric sulphate and glutaraldehyde as pulpotomy agent. International Journal of Engineering \& Scientific Research 2017; 5: 76.

2. Vij R, Coll JA, Shelton P, Farooq NS. Caries control and other variables associated with success of primary molar vital pulp therapy. Pediatric Dentistry 2004; 26: 214-220.

3. Roza H, Farid A. A Histopathological Comparison of Pulpotomy with Sodium Hypochlorite and Formocresol. Iranian Endodontic Journal 2012; 7: 60-62.

4. Pinto AS, De Araujo FB, Franzon R, Figueiredo MC, Henz S, Garcia-Godoy F, et al. Clinical and microbiological effect of calcium hydroxide protection in indirect pulp capping in primary teeth. American Journal of Dentistry 2006; 19(6): 382-386.

5. Sofrata, A., Santangelo, E.M., Azeem, M., Borg-Karlson, A.-K., Gustafsson, A., Pütsep, K. Benzyl isothiocyanate, a major component from the roots of Salvadora persica is highly active against Gram-negative bacteria. PLoS One 2011; 6 (8): e23045.

6. Ezoddini-Ardakani F. Efficacy of Miswak (salvadora persica) in preventing dental caries 2010; 2(5): 499-503.

7. Fallah M, Fallah F, Kamalinejad M, Malekan MA, Akhlaghi $\mathrm{Z}$ and Esmaeili M. The antimicrobial effect of aquatic extract of Salvadora persica on Mycobacterium bovis in vitro. International Journal of Mycobacteriology 2015; 4(1): 167-168.
8. Chelli-Chentouf N, Touil Meddah AT, Mullie C, Aoues A and Meddah B. In vitro and in vivo antimicrobial activity of Algerian Hoggar Salvadora persica L. extracts against microbial strains from children's oral cavity. Journal of Ethnopharmacology 2012; 144(1): 57-66.

9. Wolinsky, L.E. and Sote, E.O. Isolation of natural plaque inhibiting substances from Nigerian chewing sticks. Caries Research 1984; 18(3): 216-225.

10. Akpata, E.S. and Akinrimisi, E. Antibacterial activity of extracts from some African Chewing sticks. Oral Surgery 1977; 44(5): 717-722.

11. Almas, K., Al-Bagieh, N. and Akpata, E.S. In vitro antimicrobial effects of freshly cut and 1-month old miswac (chewing stick). Biomedical Letters 1997; 56: 145-149.

12. Al-lafi, T. and Ababneh, H. The effect of the ex-tract of the Miswak (chewing sticks) used injordan and the middle east on oral bacteria. International Dental Journal 1995; 45(3): 218-222.

13. Almas, K. and Al-Zeid, Z. The immediate antimicrobial effect of a toothbrush and Miswak on cariogenic bacteria: A clinical study. Journal of Contemporary Dental Practice 2004; 5(1): 105-114.

14. El-Khodary HM, El-Ashiry EA, El-Shehaby FA and Nassar HA. Comparative study of $\mathrm{CH}$ and MTA used in apexogenesis for young first permanent molars. Current Science International 2014; 3(2): 150-158.

15. Wilken R, Botha SJ, Grobler A, Germishuys PJ. In vitro cytotoxicity of chlorhexidine gluconate, benzydamine$\mathrm{HCl}$ and povidone iodine mouthrinses on human gingival fibroblasts. SADJ 2001; 56: 455-60.

16. Murray PE, Garcia-Godoy F. Stem cell responses in tooth regeneration. Stem Cells Dev 2004; 13: 255-62.

17. Darmani H, Nusayr T, Al-Hiyasat AS. Effects of extracts of miswak and derum on proliferation of Balb/C 3T3 fibroblasts and viability of cariogenic bacteria. Int J Dent Hyg 2006; 4: 62-6.

18. Al-Fatimi M, Wurster M, Schröder G, Lindequist U. Antioxidant, antimicrobial and cytotoxic activities of selected medicinal plants from Yemen. J Ethnopharmacol 2007; 111: 657-66.

19. Ali H, König GM, Khalid SA, Wright AD, Kaminsky R. Evaluation of selected Sudanese medicinal plants for their in vitro activity against hemoflagellates, selected bacteria, HIV-1-RT and tyrosine kinase inhibitory, and for cytotoxicity. J Ethnopharmacol 2002; 83: 219-28.

20. Almas AK, Almas K. Miswak (Salvadora persica chewing stick): The natural toothbrush revisited. Odontostomatol Trop 2014; 37: 27-39. 